\title{
A cladistic analysis of the Neotropical genus Sepedonea Steyskal (Diptera: Sciomyzidae)
}

\author{
LUCIANE MARINONI \& WAYNE N. MATHIS
}

(LM) Department of Zoology, Universidade Federal do Paraná, Caixa Postal 19020, 81531-990, Curitiba, Paraná, Brazil.Email: Imarinoni@ufpr.br. (WNM) Department of Entomology, NHB 169, PO Box 37012; Smithsonian Institution, Washington, D.C. 20013-7012, USA.Email: mathisw@si.edu.

\begin{abstract}
A cladistic analysis of the 13 known species of Sepedonea Steyskal, 1973, is presented and a new species, Sepedonea giovana sp. n., is described. The monophyly of the genus is confirmed, as is the genus' sister-group relationship to Sepedomerus Steyskal, 1973. The cladistic analysis was done using NONA and a matrix of 27 adult morphological characters, including structures of the male and female terminalia. The relationships in parenthetic notation are: (S. guatemalana $(S$. veredae $(S$. lindneri (S. isthmi (S. lagoa ((S. barbosai+ S. canabravana) $((S$. neffi $(S$. giovana $+S$. guianica) $)(S$. telson $(S$. incipiens $+S$. trichotypa))))))))).
\end{abstract}

Key words: Sciomyzidae, Sepedonea, Neotropical, cladistic analysis

\section{Introduction}

The dipterous family Sciomyzidae, more commonly known as marsh or snail-killing flies, occurs essentially worldwide but is most diverse in temperate regions. As alluded by the family's "snail-killing" common name, most larvae are parasitoids or predators of aquatic, semi-aquatic, or terrestrial mollusks (Berg \& Knutson 1978, Barker et al. 2004). Some species have been considered as biological control agents for pest species of Mollusca, especially snails that are hosts of schistosomes (bilharzia) and liver flukes (Chock et al. 1961, Berg 1973, Gormally 1988, Maharaj, Appleton \& Miller 1992).

Although the breeding habits of many species have been reported (Berg \& Knutson 1978, Barker et al. 2004) and the basic taxonomy at the species level is comparatively well documented (Knutson \& Vala 2002), there is a paucity of studies on phylogenetic relationships at all levels. Marinoni \& Mathis (2000) and Knutson \& Vala (2002) presented preliminary cladistic analyses of the genera of the family, the former primarily using 
morphological characters of adults and the latter using biological characters and dividing the family into 17 behavioral groups. More recently Barker et al. (2004) presented a biological overview of the Sciomyzidae with special reference to predators and parasitoids of terrestrial gastropods. Their overview also included a reanalysis of Marinoni \& Mathis (2000). The matrix used in their analysis was modified by removing the two larval characters Marinoni \& Mathis had included and then adding seven morphological characters from adults. The higher-level topologies were consistent in both analyses. There were, however, differences in the placement of some genera within the tribe Tetanocerini. Of the monophyletic lineages that Marinoni \& Mathis (2000), Knutson \& Vala (2002) and Barker et al. (2004) identified within the Sciomyzidae, the Sepedon group, which comprises eight genera, is the most consistent and best corroborated. The eight genera in the Sepedon group are: Ethiolimnia Verbeke, Teutoniomyia Hennig, Thecomyia Perty, Sepedoninus Verbeke, Sepedonella Verbeke, Sepedon Latreille, Sepedomerus Steyskal and Sepedonea. Steyskal (1973) first recognized the Sepedon group, although it was then limited to four genera (Sepedonella, Sepedoninus, Sepedomerus and Sepedonea).

At the species level, only two cladistic studies are available: Protodictya Malloch (Marinoni \& Carvalho 1993) and Thecomyia Perty (Marinoni et al. 2003). To augment our understanding of species-level phylogeny in the Sciomyzidae and among genera of the Sepedon group in particular, we provide herein the first cladistic analysis for the 13 known species of Sepedonea. This species-level analysis builds upon the revision by Freidberg et al. (1991).

Sepedonea is readily distinguished from other sciomyzid genera (see Figs. 1-39), especially those of the Sepedon group, by the following characters (synapomorphies are identified by an *): *(1) face with dark brown spot on each ventral corner; *(2) male with the posterior surstyli fused, forming a medial structure; and (3) forefemur with at least one outstanding dorsal seta.

Sepedonea presently includes 12 species (Friedberg et al. 1991) that are known thus far only from Central and South America (Sepedonea barbosai Knutson and Bredt, $S$. canabravana Knutson and Bredt, S. guatemalana (Steyskal), S. guianica (Steyskal), S.incipiens Freidberg, Knutson and Abercrombie, S. isthmi (Steyskal), S. lagoa (Steyskal), S. lindneri (Hendel), S. neffi Freidberg, Knutson and Abercrombie, S. telson (Steyskal), S. trichotypa Freidberg, Knutson and Abercrombie, S. veredae Freidberg, Knutson and Abercrombie). We describe a $13^{\text {th }}$ species herein that was discovered among specimens collected in central and southern Brazil and northern Argentina.

The biology of all species, except S. barbosai Knutson and Bredt, S. canabravana Knutson and Bredt, S. guianica (Steyskal), S. neffi, Freidberg et al., and S. veredae Freidberg et al., is known and relatively well documented (Neff \& Berg 1966, Knutson \& Valley 1978, Freidberg et al. 1991); this includes larval morphology and behavior (predaceous on freshwater, non-operculate snails; the descriptions of immatures that were published by Freidberg et al. (1991) for S. guianica are actually of the new species described below). 
The larvae of Sepedonea are similar to those of Sepedon and Sepedomerus (Neff and Berg, 1966). The most obvious larval difference is the shape of the dorsal accessory tooth of the cephalopharyngeal skeleton, which in Sepedonea is larger and more darkly sclerotized, and the remaining teeth are smaller and only lightly sclerotized. In Sepedomerus and Sepedon, the accessory teeth are subequal in size and evenly sclerotized, usually lightly (Freidberg et al. 1991).

\section{Materials and Methods}

The terminology for structures of the male terminalia follows Cumming et al. (1995), and for chaetotaxy and other preabdominal features we use the terminology of McAlpine (1981).

Because specimens of Sepedonea are similar morphologically, differing primarily in several features of the male postabdomen, the new species description is diagnostic, referring mostly to structures of the male terminalia.

Although most specimens are in the National Museum of Natural History, Smithsonian Institution, Washington, D.C. (USNM), we also studied numerous specimens from the following collection: Coleção Entomológica Pe. Jesus S. Moure (DZUP), Departamento de Zoologia, Universidade Federal do Paraná, Curitiba, Paraná, Brazil.

A distribution map was made using ESRI ArcView8 GIS 3.2 ®. Longitude and latitude coordinates were obtained for the locality where each specimen was collected. Longitude and latitude were obtained directly from the specimen labels, or for specimen labels lacking longitude and latitude, gazetteers and maps were consulted to determine the geographic coordinates. The geographic coordinates were entered into ESRI ArcView tables. The specimen locales were plotted on a world land projection, presented within ESRI ArcView layouts and exported as encapsulated postscript (EPS) files.

The cladistic analysis was performed using NONA®, and the program Winclada ${ }^{\circledR}$ (Kevin Nixon, 1999) provided the Windows format to NONA. Multistate characters were treated as unordered in the analyses. All 13 species of Sepedonea were used in the analysis, and Sepedon armipes Loew, Sepedomerus macropus (Walker) and Sepedomerus bipuncticeps (Malloch) were used as outgroups. These species were selected because Sepedomerus is the sister group of Sepedonea, and Sepedon is the sister group of Sepedonea + Sepedomerus in the cladogram of the Sciomyzidae (Marinoni and Mathis 2000; Barker et al. 2004). The following characters are synapomorphies for these three genera: (1) $6^{\text {th }}, 7^{\text {th }}$ and $8^{\text {th }}$ sternites of female terminalia completely fused; (2) lunule greatly exposed; and (3) two notopleural setae (a reversal). A matrix with 27 morphological adult characters was produced, including characters based on structures of the male and female terminalia. 


\section{Systematics}

Sepedonea giovana, sp. nov. (Figs. 1-11; 27; 41)

Sepedonea guianica of authors, not Steyskal [misidentification]. Knutson et al. 1976: 11 [Neotropical catalog; partim]. Knutson \& Valley 1978: 198 [review; partim]. Freidberg et al. 1991: 16 [revision; partim].

Sepedonea vau. Mello and Bredt 1978: 1459 [nomen nudum; phenology].

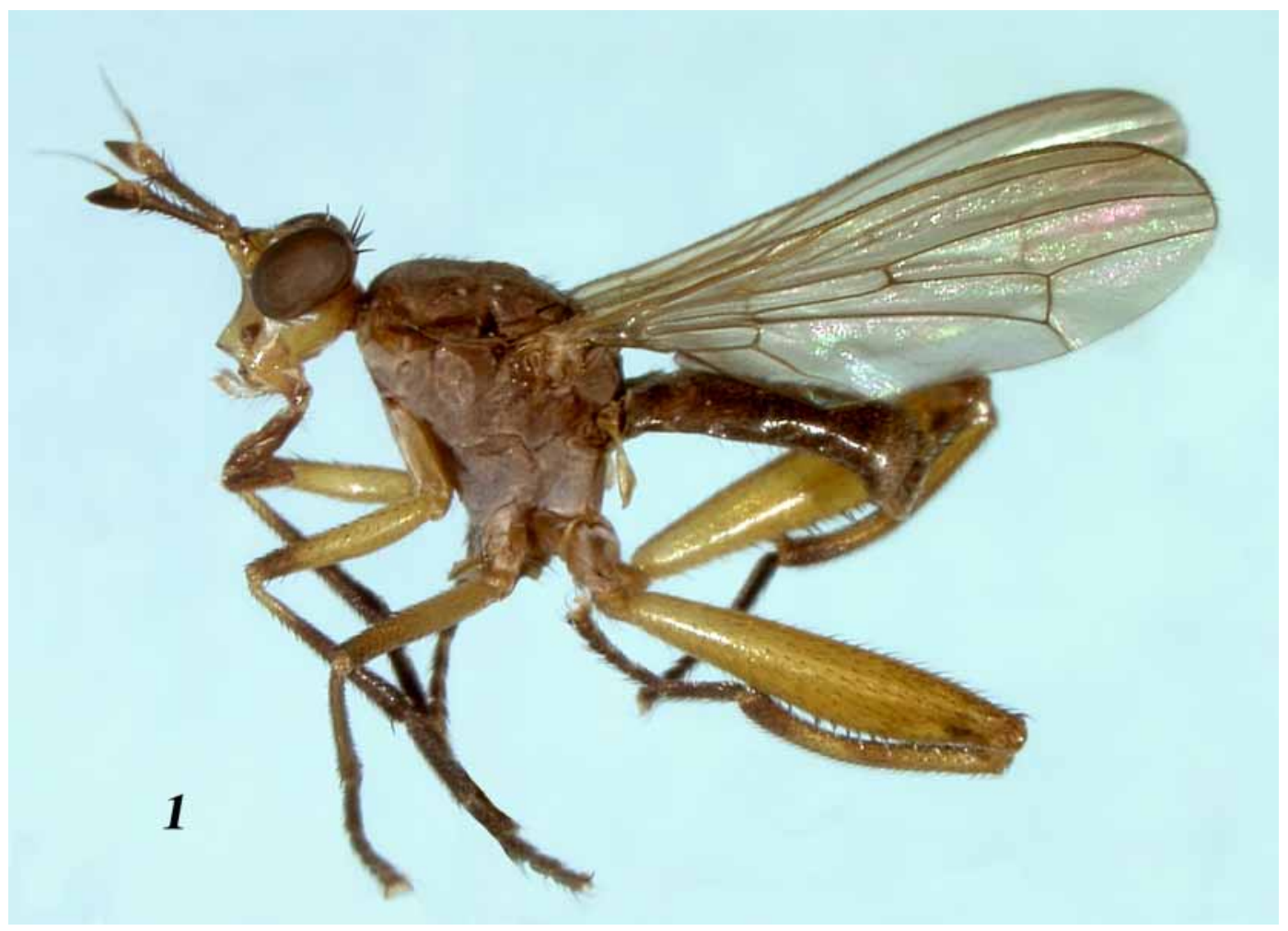

FIGURE 1. Habitus of Sepedonea giovana sp. n.

Diagnosis. This species is distinguished from congeners (described in Freidberg et al., 1991) especially $S$. guianica, by the following combination of characters: Mesonotum grayish black; setulae near posterior thoracic spiracle moderately numerous, weak but well developed. Wing (Fig. 5) infuscate, clouded. Midfemur bearing 3-5 spine-like setae posteroventrally; hindfemur with more or less discrete, usually dark, preapical lateral mark.

Description. Adult. Head: Ocellar seta absent; postocellar seta absent. Fronto-orbital spot absent; orbito-antennal spot absent; face with a large brown spot at ventral corner. 


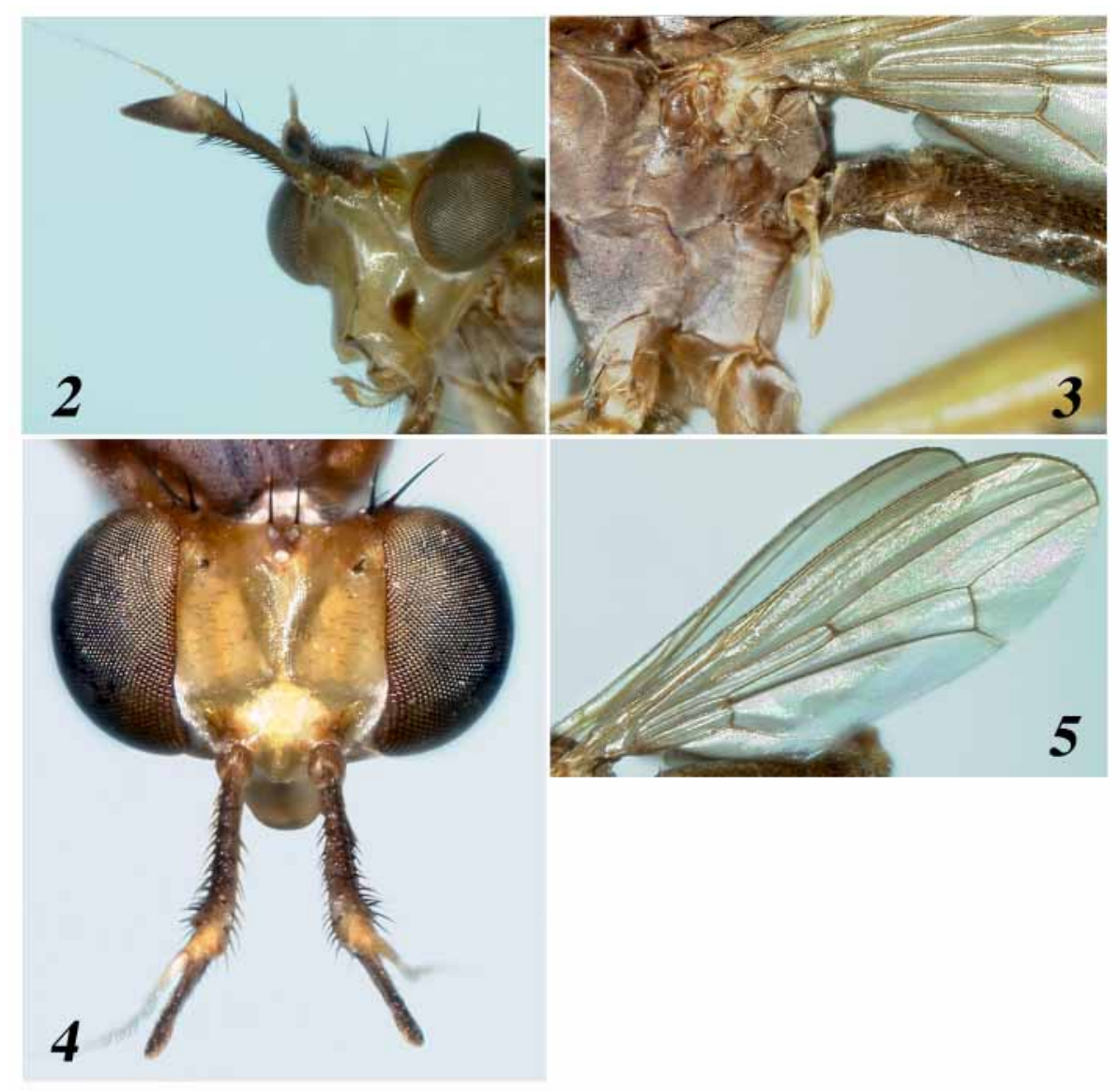

FIGURES 2-5. Sepedonea giovana sp. n. 2. Head, frontal view; 3. Posterior spiracle; 4. Head, dorsal view; 5 . Wings.

Thorax: Mesonotum grayish black; postpronotum brownish; setulae near posterior spiracle moderately strong and dense; setation near posterior spiracle weakly developed; setae on katatergal callus absent. Wing: Length 5.0-6.0 mm; brownish, usually clouded anteroapically and over crossveins $\mathrm{r}-\mathrm{m}$ and $\mathrm{dm}-\mathrm{cu}$. Legs: Forefemur bearing at least 1 well-developed seta; midfemur usually bearing 3-6 spine-like setae posteroventrally, not extended beyond half distance to base, lacking setae along anterior surface; hindcoxa bearing short setulae posteriorly, mostly restricted to medial portion; hindfemur claviform, usually with dark, preapical marks, height/width ratio 4.5-5.0; hindtibia with a spinelike projection but lacking a distinctive seta at ventroapical margin.

Abdomen: Male terminalia (Figs. 6-10): Posterior margin of $4^{\text {th }}$ sternite deeply emarginate, with 2 lateral processes (Fig. 7); anterior plate of $5^{\text {th }}$ sternite not reduced, with wide, indented flange at posteromedial margin folded ventrally (Fig. 6), posterior portion with a pair of moderately-sized processes; distiphallus (Fig. 8) sinuous, with posteroventral angle covered by large flat, setulose epiphallus; anterior surstylus small, indistinct; 
posterior surstyli completely fused to form a medial structure, this structure without a medial lobe; posterior surstylus with lateral lobe moderately strongly curved anteriorly (Fig. 9); epiphallus large; distiphallus absent. Female synsternite (Figs. 11; 27): Posterior margin in ventral view with ventral surface more or less straight, and with posterior ridge distinctly projected, rounded (Fig. 11); spermathecal duct at junction with spermatheca divided in 2 portions, portion closest to spermatheca wide (Fig. 27).
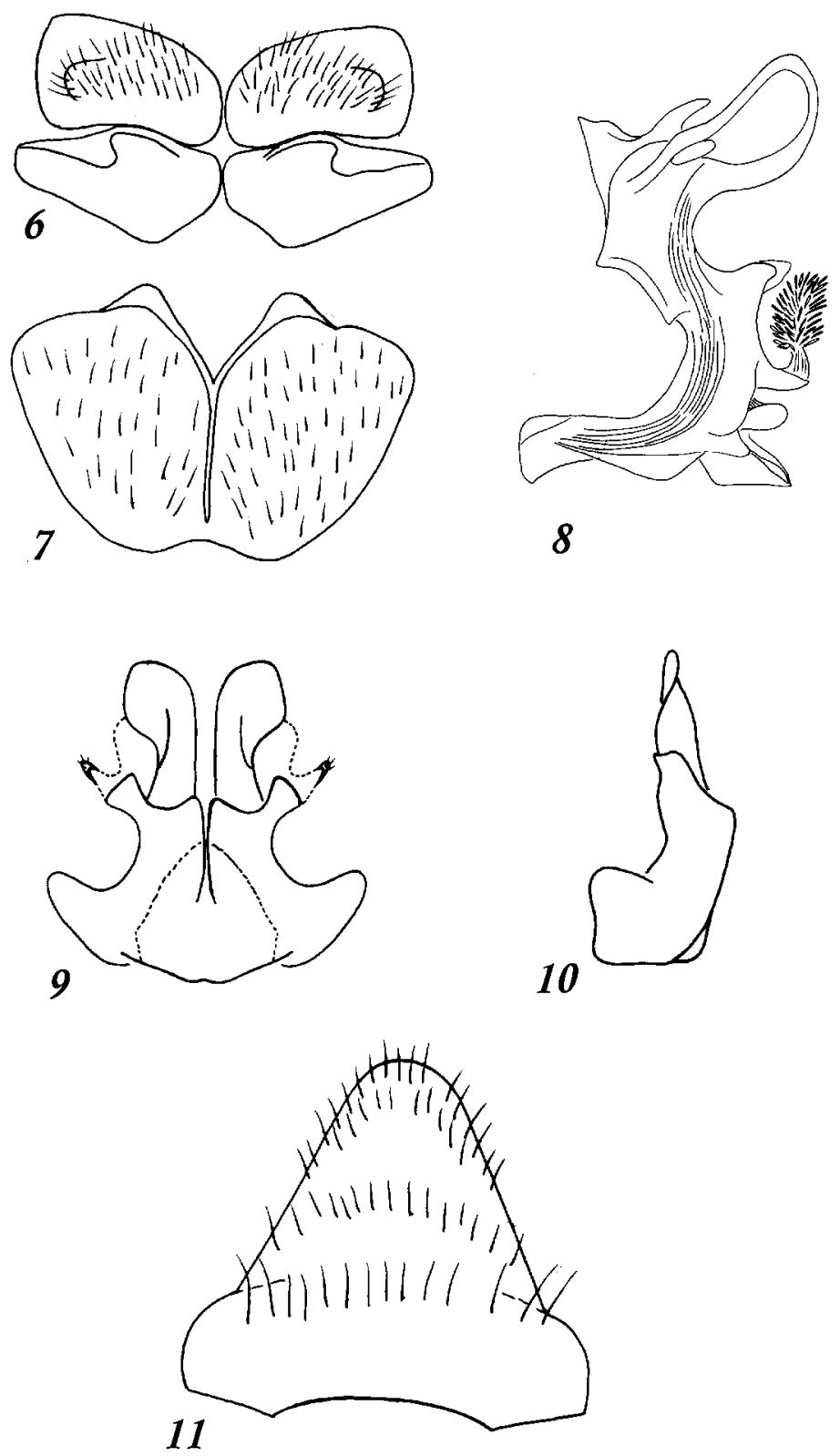

FIGURES 6-11. Sepedonea giovana sp. n. 6 . male $5^{\text {th }}$ sternite; 7. male $4^{\text {th }}$ sternite; 8 . distiphallus lateral view; 9. posterior surstyli, posterior view; 10. posterior surstyli, lateral view; 11. female synsternite, ventral view. 
Type specimens. The holotype male is labeled "BRAZIL: Minas Gerais: $17 \mathrm{~km} \mathrm{~N}$ of Belo Horizonte [4356'W. 1945'S] C. O. Berg 18-23 July 1964/HOLOTYPE ơ Sepedonea giovana Marinoni \& Mathis [red]." The holotype is directly pinned, is in excellent condition, and is deposited in the USNM. Twenty-five male paratypes bear the same locality label as the holotype (DZUP, USNM). Other paratypes are as follows: BRAZIL. Minas

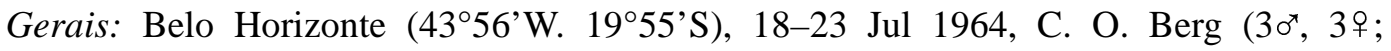

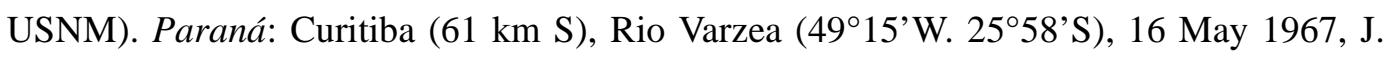

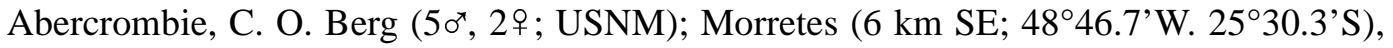
4-17 May 1967, J. Abercrombie, C. O. Berg (1; USNM); Praia do Leste (48²8’ W.

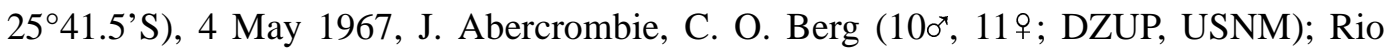
Iguassu at Araucaria (51 $12^{\prime}$ W. $30^{\circ} 48^{\prime}$ 'S), 1 May 1967, J. Abercrombie, C. O. Berg (1 $0^{\star}$; USNM). Rio Grande do Sul: Porto Alegre (87 km S; 51 ${ }^{\circ} 12^{\prime}$ W. 3048’S), 10 May 1967, J. Abercrombie, C. O. Berg (1우 USNM). Santa Catarina: Lajes (5 km W; 50²1.7’W. 27²8’S), 6 May 1967, J. Abercrombie, C. O. Berg (1 $0^{x}$; USNM); Lajes (30 km S; 50¹9’W. 2804.2’'S), 12 May 1967, J. Abercrombie, C. O. Berg (1우 USNM). São Paulo: São José do Rio Preto (48²3’W. 2048.1'S), 27 Jul 1966, N. Papavero (1 $10^{\star}$; USNM).

Type locality. Brazil. Minas Gerais: Belo Horizonte (17 km N; 435' W. 1945'S).

Other specimens examined. ARGENTINA. Tucumán: Monteros $\left(65^{\circ} 30^{\prime} \mathrm{W}\right.$.

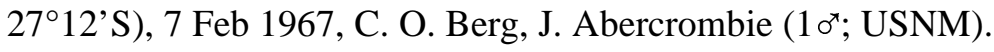

BRAZIL. Minas Gerais: Jockey Club, 23 Aug-15 Sep 1966, C. O. Berg (120, 3 우 USNM).

Locality records from Mello \& Bredt (1978). BRAZIL. Distrito Federal: Núcleo Bandeirantes (47 58'W. 1552'S), 11 Nov 1974, D. A. Mello, A. Bredt; Riberão Extrema, DF 21, 6 Feb 1974, D. A. Mello, A. Bredt. Minas Gerais: Hipódromo Serra Verde, Santa

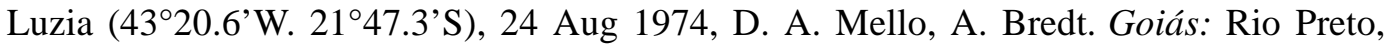
Formosa (47²0’W. 15³2’S), 19 Jun 1974, Jan-May, Jul-Oct, Dec 1975, 1976, D. A. Mello, A. Bredt.

Distribution (Fig. 41). Neotropical: Argentina (Tucumán) and Brazil (Goiás, Distrito Federal, Espirito Santo, Minas Gerais, Paraíba, Paraná, São Paulo).

Etymology. The species epithet, giovana, is a noun in apposition and is named after the delightful daughter of the first author and her husband, Sionei Ricardo Bonatto, whose support is also appreciated.

Remarks. Externally, the species of Sepedonea are difficult to distinguish and reference to structures of the male terminalia is usually needed to determine species accurately.

The distribution map includes a few localities that we extracted from Mello \& Bredt (1978), as noted above. We did not include localities they listed that may apply to another species, such as $S$. guianica, as we did not have access to these specimens to verify determinations of species. 


\section{Characters and character states used in the cladistic analysis}

The characters used in the analysis are listed and discussed below. The letters A and P represent the relative apomorphic and plesiomorphic states respectively.

\section{HEAD}

1. Facial color at ventral corner: $\mathrm{P}(0)$ plain, lacking a spot; $\mathrm{A}(1)$ with a brown spot.

2. Ocellar seta: $\mathrm{P}(0)$ present; A (1) absent.

3. Postocellar setae: P (0) present; A (1) absent.

4. Fronto-orbital spot: $\mathrm{P}(0)$ present; A (1) absent.

5. Orbito-antennal spot: $\mathrm{P}(0)$ present; A (1) absent.

\section{THORAX}

6. Setation of forefemur: $\mathrm{P}(0)$ absent; $\mathrm{A}(1)$ bearing at least 1 well-developed dorsal seta.

7. Setation of midfemur along anterior surface: $\mathrm{P}(0)$ absent; $\mathrm{A}(1)$ present.

8. Setation of male hindcoxal strap: P (0) setulae restricted medially; A (1) setulae restricted posterodorsally.

9. Hindtibia: $\mathrm{P}(0)$ without a spinelike projection; A (1) with a spinelike projection.

10. Hindtibia with a distinctive seta at the ventroapical margin: $\mathrm{P}(0)$ absent; $A(1)$ present.

11. Male hindfemur height/width: $\mathrm{P}(0)$ 4.5-5.0; A (1) 7.5-8.0.

12. Setation near posterior spiracle: $P(0)$ setulae weak; A (1) setulae strong.

13. Setae of katatergal callus: $P(0)$ present; $A(1)$ absent.

14. Shape of male hindfemur: P (0) claviform; A (1) parallel sided.

\section{MALE TERMINALIA}

15. Posterior margin of male 4th sternite: $P(0)$ without a process; A (1) with a simple, medial process; A (2) with a bilobed, medial process; A (3) with two lateral processes.

16. Shape of posterior margin of male 5th sternite: P (0) straight; A (1) folded ventrally.

17. Fused status of posterior surstylus: P (0) unfused; A (1) partly fused; A (2) completely fused to form a medial structure.

18. Shape of posterior surstylus (when applicable): P (0) as in Fig. 19; A (1) as in Figs. 14, 16, 18, 21, 22; (2) as in Figs. 12, 13; (3) as in Figs. 17, 23; (4) as in Figs. 15, 24; (5) as in Fig. 20.

19. Anterior surstylus: P (0) absent; A (1) vestigial; A (2) small; A (3) well developed.

20. Plates at posterior portion of male $5^{\text {th }}$ sternite: $\mathrm{P}(0)$ not reduced; A (1) reduced.

21. Posterior portion of male $5^{\text {th }}$ sternite: P (0) without a process; A (1) with a pair of moderately-sized processes, not digitiform; A (2) with a pair of digitiform processes; A (3) with two pairs of well-developed digitiform processes.

22. Epiphallus: P (0) not evident; A (1) small; A (2) large

23. Epandrial prong: P (0) absent; A (1) small; A (2) well developed.

24. Distiphallus with a ventral process: $P(0)$ absent; $A$ (1) present

25. Distiphallus: P (0) not short and straight; A (1) short and straight. 

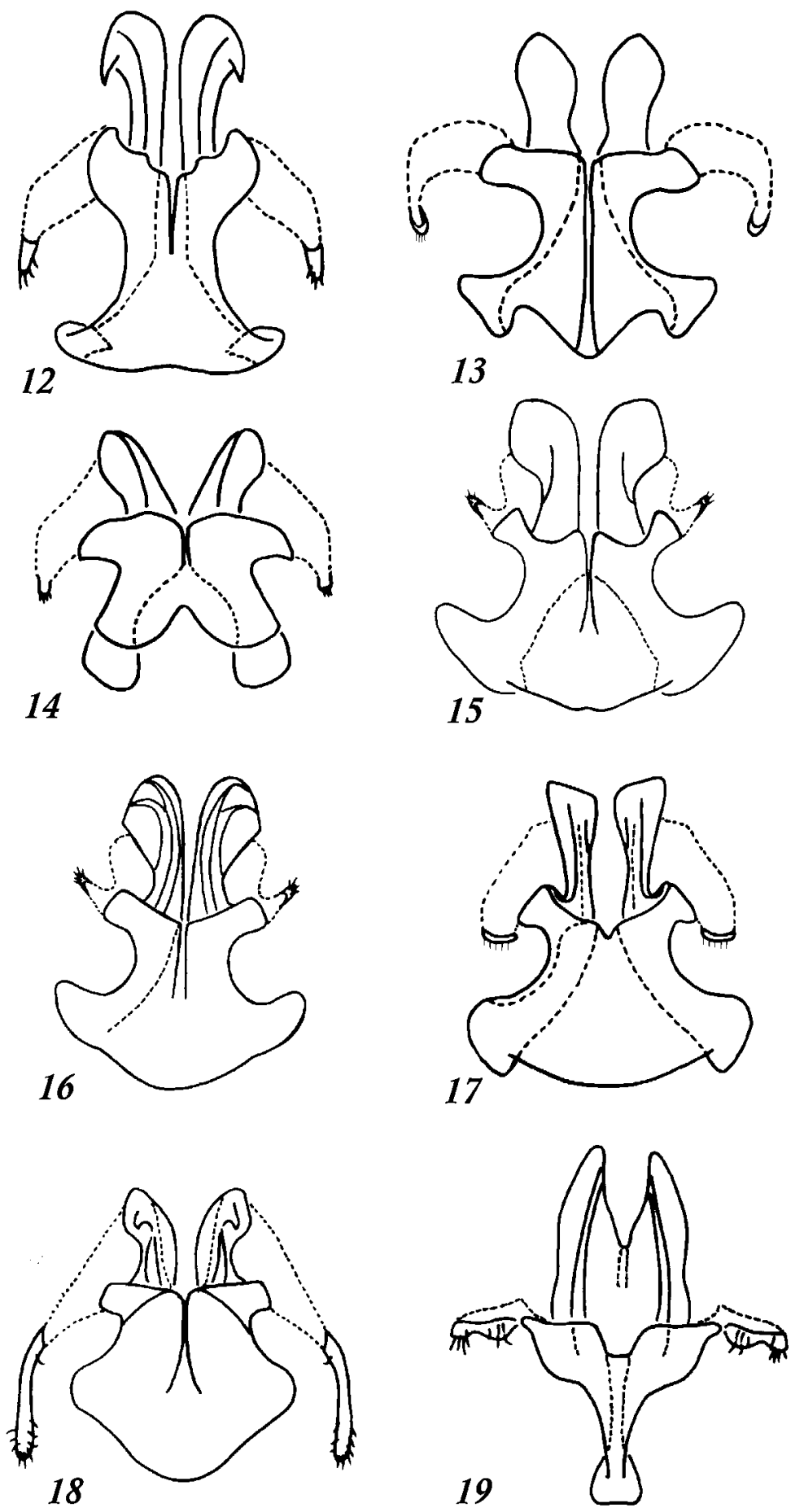

FIGURES 12-19. Posterior surstyli, posterior view. 12. Sepedonea barbosai; 13. S. canabravana; 14. S. giovana; 15. S. guatemalana; 16. S. guianica; 17. S. incipiens; 18. S. isthmi; 19. S. lagoa. 

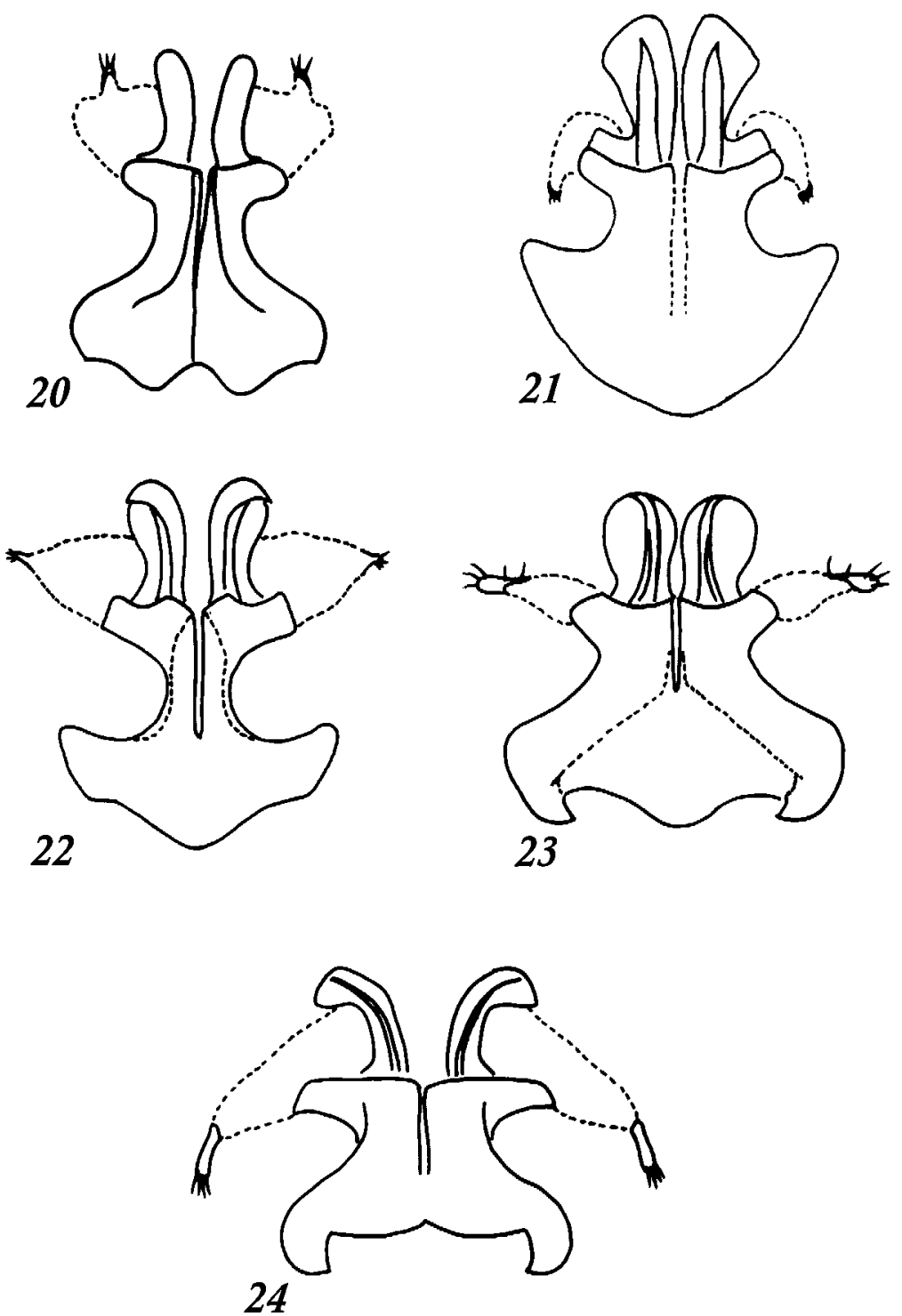

FIGURES 20-24. Posterior surstyli, posterior view. 20. S. lindneri; 21. S. neffi; 22. S. telson; 23. S. trichotypa; 24. S. veredae.

\section{FEMALE TERMINALIA}

26. Posterior margins of female synsternite 6, 7, and 8: P (0) straight; A (1) convex; A (2) concave; A (3) with a medial expansion.

27. Spermathecal duct at the junction with the spermatheca (Figs. 25-39): (0) not divided; (1) divided into two portions, the portion closest to the spermatheca narrower; (2) divided into two portions, the portion closest to the spermatheca wider. 


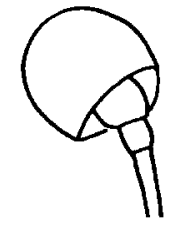

25

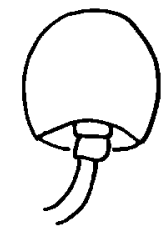

29

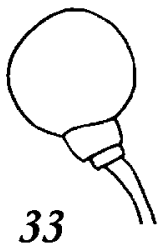

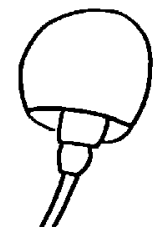

26

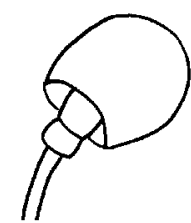

30

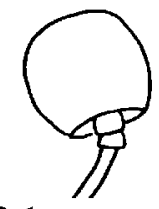

34

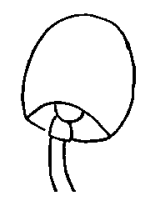

27

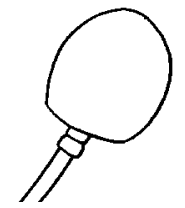

28
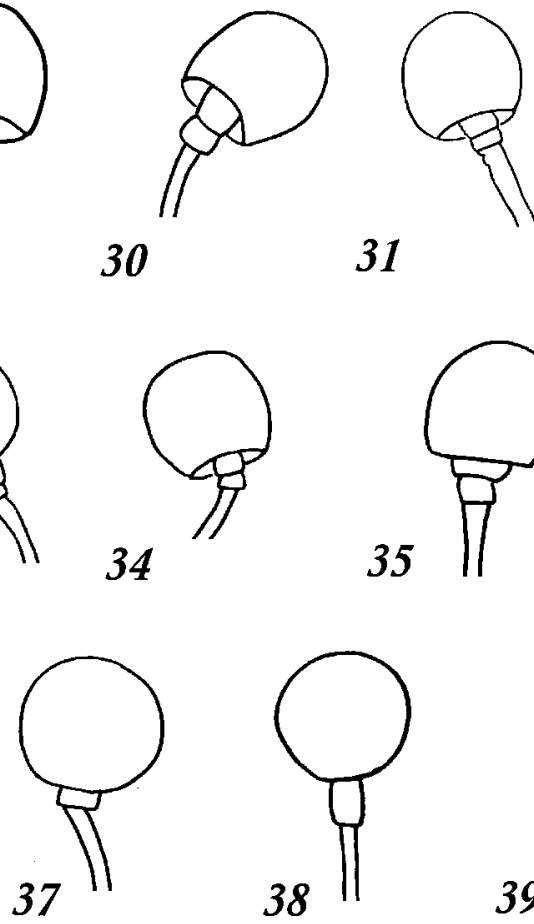

31

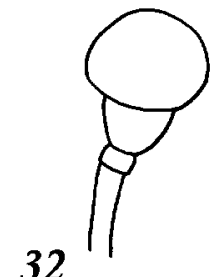

32
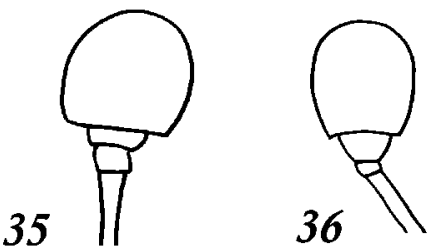

\section{6}

39

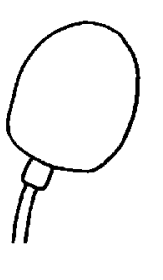

FIGURES 25-39. Spermathecae. 25. Sepedonea barbosai; 26. S. canabravana; 27. S. giovana; 28. S. guatemalana; 29. S. guianica; 30. S. incipiens; 31. S. isthmi; 32. S. lagoa; 33. S. lindneri; 34. S. neffi; 35. S. telson; 36. S. trichotypa; 37. S. veredae; 38. Sepedomerus macropus; 39. Sepedon armipes.

\section{Relationships obtained with comments on the ecology, behavior and distribution}

The analysis (1000 replications) resulted in a single cladogram (Fig. 40) with a length of 60 steps with consistency and retention indices of 0.70 and 0.75 respectively.

The relationships among the genera Sepedon, Sepedomerus and Sepedonea are confirmed. In Marinoni \& Mathis (2000), Knutson \& Vala (2002) and Barker et al. (2004), these genera are closely related and form a monophyletic group. In parenthetic notation the relationship among these genera is: Sepedon (Sepedonea + Sepedomerus). In our analysis a sister-group relationship between Sepedonea and Sepedomerus is established based on: (2) the absence of ocellar setae; (4) the absence of a fronto-orbital spot; and (9) the presence of a spine-like projection on the hindtibia. 
TABLE 1. Matrix of characters and taxa used in the cladistic analysis of Sepedonea (numbers for characters correspond with those used in the text).

\begin{tabular}{|c|c|c|c|c|c|c|c|c|c|c|c|c|c|c|c|c|c|c|c|c|c|c|c|c|c|c|c|}
\hline Гаха/Chara & {$\left[\begin{array}{l}0 \\
1\end{array}\right.$} & $\begin{array}{l}\mathbf{0} \\
2 \\
\end{array}$ & $\begin{array}{l}0 \\
3\end{array}$ & $\begin{array}{l}0 \\
4 \\
\end{array}$ & $\begin{array}{l}\mathbf{0} \\
5\end{array}$ & $\begin{array}{l}0 \\
6 \\
\end{array}$ & $\begin{array}{l}0 \\
7\end{array}$ & $\begin{array}{l}\mathbf{0} \\
8\end{array}$ & $\begin{array}{l}\mathbf{0} \\
9\end{array}$ & $\begin{array}{l}1 \\
\mathbf{0}\end{array}$ & $\begin{array}{l}1 \\
1\end{array}$ & $\begin{array}{l}1 \\
2\end{array}$ & \begin{tabular}{l|l}
1 \\
3
\end{tabular} & $\begin{array}{l}1 \\
4\end{array}$ & $\begin{array}{l}1 \\
5\end{array}$ & $\begin{array}{l}1 \\
6 \\
\end{array}$ & $\begin{array}{l}1 \\
7 \\
\end{array}$ & $\begin{array}{l}1 \\
8\end{array}$ & $\begin{array}{l}1 \\
9\end{array}$ & $\begin{array}{l}2 \\
\mathbf{0}\end{array}$ & $\begin{array}{l}2 \\
1\end{array}$ & $\begin{array}{l}2 \\
2\end{array}$ & \begin{tabular}{l|l}
2 & 2 \\
3 & 2
\end{tabular} & & \begin{tabular}{l|l}
2 & 2 \\
5 & 6 \\
\end{tabular} & & $\begin{array}{l}2 \\
7\end{array}$ \\
\hline Sepedon armipes & 0 & 0 & 0 & 0 & 0 & 0 & 0 & 0 & 0 & 0 & 0 & 0 & 0 & 0 & 0 & 0 & 0 & $?$ & 0 & 0 & 0 & 0 & $0 \mid c$ & 0 & $0 \mid 0$ & & 0 \\
\hline Sepedomerus macropus & 0 & 1 & 1 & 1 & 0 & 0 & 1 & 0 & 1 & 1 & 1 & 0 & 0 & 1 & 0 & 0 & 0 & $?$ & 0 & 0 & 0 & 0 & 0 & 0 & 0 & & 0 \\
\hline Sepedomerus bipuncticeps & 0 & 1 & 1 & 1 & 0 & 0 & 1 & 0 & 1 & 1 & 1 & 0 & 0 & 1 & 0 & 0 & 0 & $?$ & 0 & 0 & 0 & $?$ & 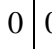 & 0 & $0 \mid 0$ & & 0 \\
\hline Sepedonea barbosai & 1 & 1 & 0 & 1 & 1 & 1 & 0 & 1 & 1 & 0 & 0 & 0 & 1 & 0 & 1 & 0 & 2 & 2 & 1 & 0 & 0 & 2 & 2 & 0 & \begin{tabular}{l|l}
0 & 1 \\
\end{tabular} & 1 & 1 \\
\hline S. canabravana & 1 & 1 & 0 & 1 & 1 & 1 & 0 & 1 & 1 & 0 & 0 & 0 & 1 & 0 & 1 & 0 & 2 & 2 & 1 & 0 & 3 & 1 & 1 & 0 & $0 ?$ & $?$ & 1 \\
\hline S. giovana & 1 & 1 & 0 & 1 & 1 & 1 & 0 & 0 & 1 & 0 & 0 & 0 & 1 & 0 & 3 & 1 & 2 & 1 & 2 & 0 & 1 & 2 & 1 & 0 & \begin{tabular}{l|l}
0 & 1 \\
\end{tabular} & & 1 \\
\hline S. guatemalana & 1 & 1 & 0 & 1 & 1 & 1 & 0 & 0 & 1 & 0 & 0 & 0 & 1 & 0 & 1 & 0 & 1 & 4 & 2 & 0 & 0 & 2 & 2 & 1 & $0 \mid 0$ & 0 & 1 \\
\hline S. guianica & 1 & 1 & 0 & 1 & 1 & 1 & 0 & 0 & 1 & 0 & 0 & 0 & 1 & 0 & 3 & 1 & 2 & 1 & 2 & 0 & 1 & 2 & 1 & 0 & 0 & 1 & 1 \\
\hline S. incipiens & 1 & 1 & 0 & 1 & 1 & 1 & 0 & 0 & 1 & 0 & 0 & 1 & 1 & 0 & 2 & 1 & 2 & 3 & 2 & 0 & 1 & 1 & 1 & 0 & 0 & 1 & 2 \\
\hline S. isthmi & 1 & 1 & 0 & 1 & 1 & 1 & 0 & 0 & 1 & 0 & 0 & 0 & 1 & 0 & 0 & 0 & 2 & 1 & 3 & 0 & 0 & 2 & 2 & 0 & 0 & 2 & 2 \\
\hline S. lagoa & 1 & 1 & 0 & 1 & 1 & 1 & 0 & 1 & 1 & 0 & 0 & 0 & 1 & 0 & 0 & 0 & 2 & 0 & 1 & 1 & 0 & 0 & 0 & 0 & 1 & 1 & 2 \\
\hline S. lindneri & 1 & 1 & 0 & 1 & 1 & 1 & 0 & 0 & 1 & 0 & 0 & 0 & 1 & 0 & 3 & 0 & 2 & 5 & 2 & 0 & 2 & 2 & 0 & 1 & 0 & 2 & 2 \\
\hline S. neffi & 1 & 1 & 0 & 1 & 1 & 1 & 0 & 1 & 1 & 0 & 0 & 0 & 1 & 0 & 1 & 1 & 2 & 1 & 2 & 0 & 2 & 1 & 1 & 0 & 0 & 1 & 1 \\
\hline S. telson & 1 & 1 & 0 & 1 & 1 & 1 & 0 & 1 & 1 & 0 & 0 & 0 & 1 & 0 & 2 & 1 & 2 & 1 & 2 & 0 & 1 & 2 & 1 & 0 & 0 & 1 & 2 \\
\hline S. trichotypa & 1 & 1 & 0 & 1 & 1 & 1 & 0 & 1 & 1 & 0 & 0 & 1 & 1 & 0 & 2 & 1 & 2 & 3 & 1 & 0 & 1 & 2 & 1 & 0 & 0 & 1 & 2 \\
\hline S. veredae & 1 & 1 & 0 & 1 & 1 & + & 0 & 0 & 1 & 0 & 0 & 0 & 1 & 0 & 0 & 0 & 1 & 4 & 1 & 0 & $\cdot$ & 1 & 1 & 1 & 0 & 2 & 0 \\
\hline
\end{tabular}

These three genera are in the same behavioral group (group number 11 of Knutson \& Vala 2002: 147). Sepedonea and Sepedomerus are exclusively predators on non-operculate snails that live "... at or just below the water surface, just above the surface on emergent vegetation, and exposed on wet to damp surfaces." Some species of the genus Sepedon belong to other behavioral groups (see Knutson \& Vala 2002). Barker et al. (2004) established nine "eco-groups" within Sciomyzidae. These groups were defined on the basis of habitat, behavior and morphological characters of the immature stages. Both Sepedomerus and Sepedonea are in a separate eco-group from Sepedon.

In our cladistic analysis the monophyly of the genus Sepedonea is confirmed and is based on the following characters: (1) the presence of a brown spot at the ventral corner of the face; (5) the absence of an orbito-antennal spot; (6) the forefemur bearing at least one well-developed dorsal seta; (13) the katatergite callus bearing setae; (19) the presence of an anterior surstylus; (21) the posterior surstyli being fused to form a medial structure; and (26) the spermathecal duct at the junction with the spermatheca divide into two portions. The presence of a brown spot at the ventral corner of the face and the fusion of the posterior surstyli are unique characters among all sciomyzid genera.

For species of Sepedomerus (S. macropus and S. bipuncticeps were studied), the characters that establish the monophyly of the genus are: (3) the absence of a postocellar seta; 
(7) the presence of setation on the midfemur along the medial surface; (10) the presence of a distinctive seta on the hind tibia along the ventroapical margin; (11) the sizes of the male hind femur (height 7.5-8.0 times the width), which is (14) parallel sided.

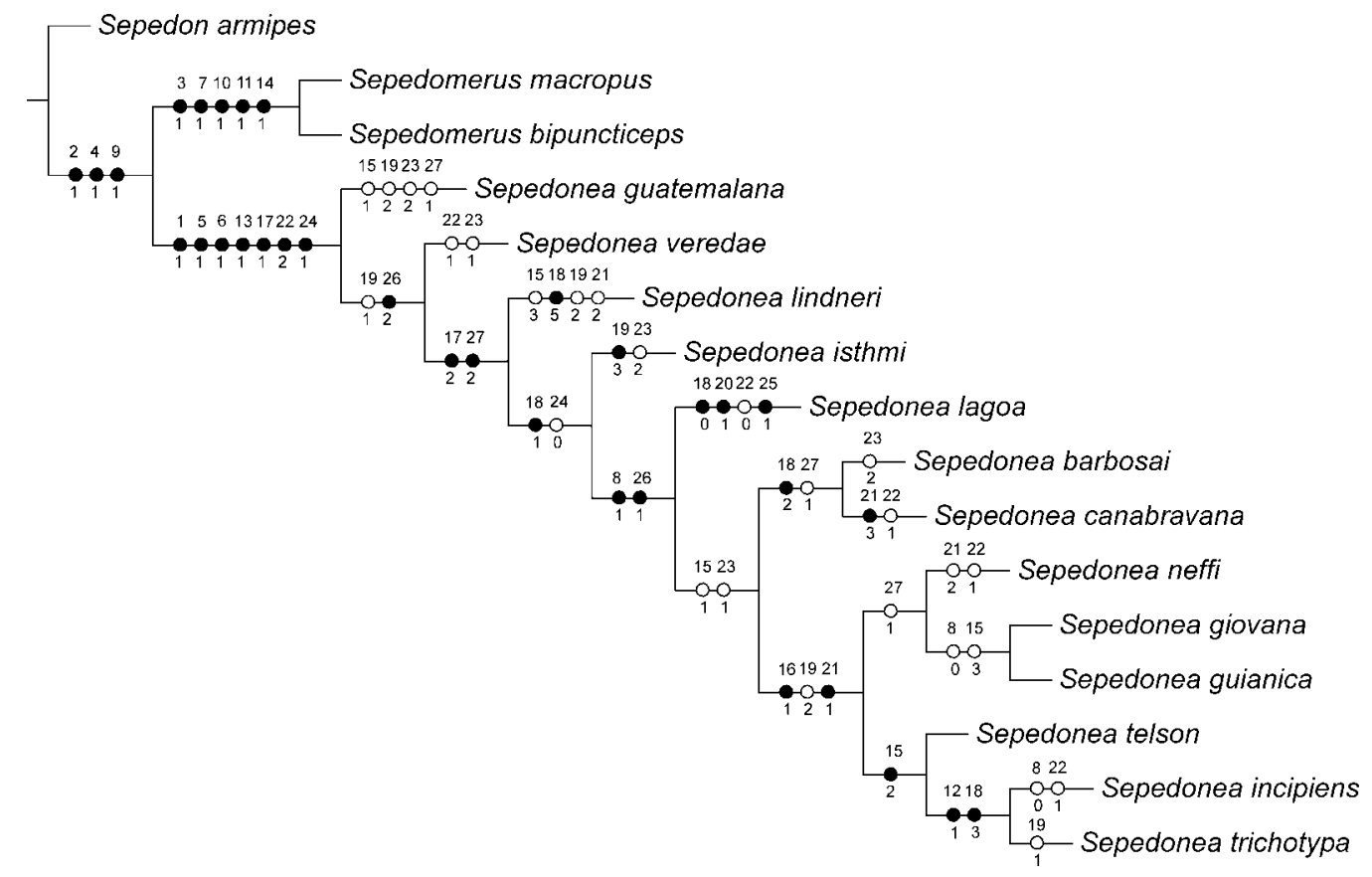

FIGURE 40. Cladogram of the Sepedonea species obtained with the outgroups Sepedomerus macropus, Sepedomerus bipuncticeps and Sepedon armipes. Length of 60 steps, consistency index 0.70 and retention index 0.75 .

The basal lineage on the cladogram comprises a single species, S. guatemalana. This species has the northernmost distribution in the genus, ranging from Chiapas (Mexico) to Costa Rica. The northernmost distribution of this species in part prompted Freidberg et al. (1991) to suggest two hypotheses: 1. the species had evolved relatively late, or, 2. the species was an early offshoot of the genus and is the sister group of all remaining species. They also mentioned the weak fusion of the posterior surstyli as a character supporting the latter hypothesis. Our analysis corroborates the latter hypotheses, i.e., that S. guatemalana is the most primitive lineage and species within the genus.

The next lineage, $S$. veredae, is also a single species. This species has been recorded from central and northeastern Brazil (Pernambuco, Bahia, Mato Grosso and Espirito Santo). The clade that evolved immediately afterwards, beginning with $S$. lindneri, is supported by the presence of the surstylus being completely fused (17) and the spermathecal duct at the junction with the spermatheca being divided into two portions, the portion closest to the spermatheca wider (27). The first lineage within this group is $S$. lindneri. This species has the southernmost distribution of all species of Sepedonea, and the lineage is defined by the following homoplasious characters: (15) the posterior margin of the male 

terior portion of the male $5^{\text {th }}$ sternite has a pair of digitiform processes. An autapomorphy characterizing this lineage is: (18) the emarginate posterior margin of the posterior surstylus.

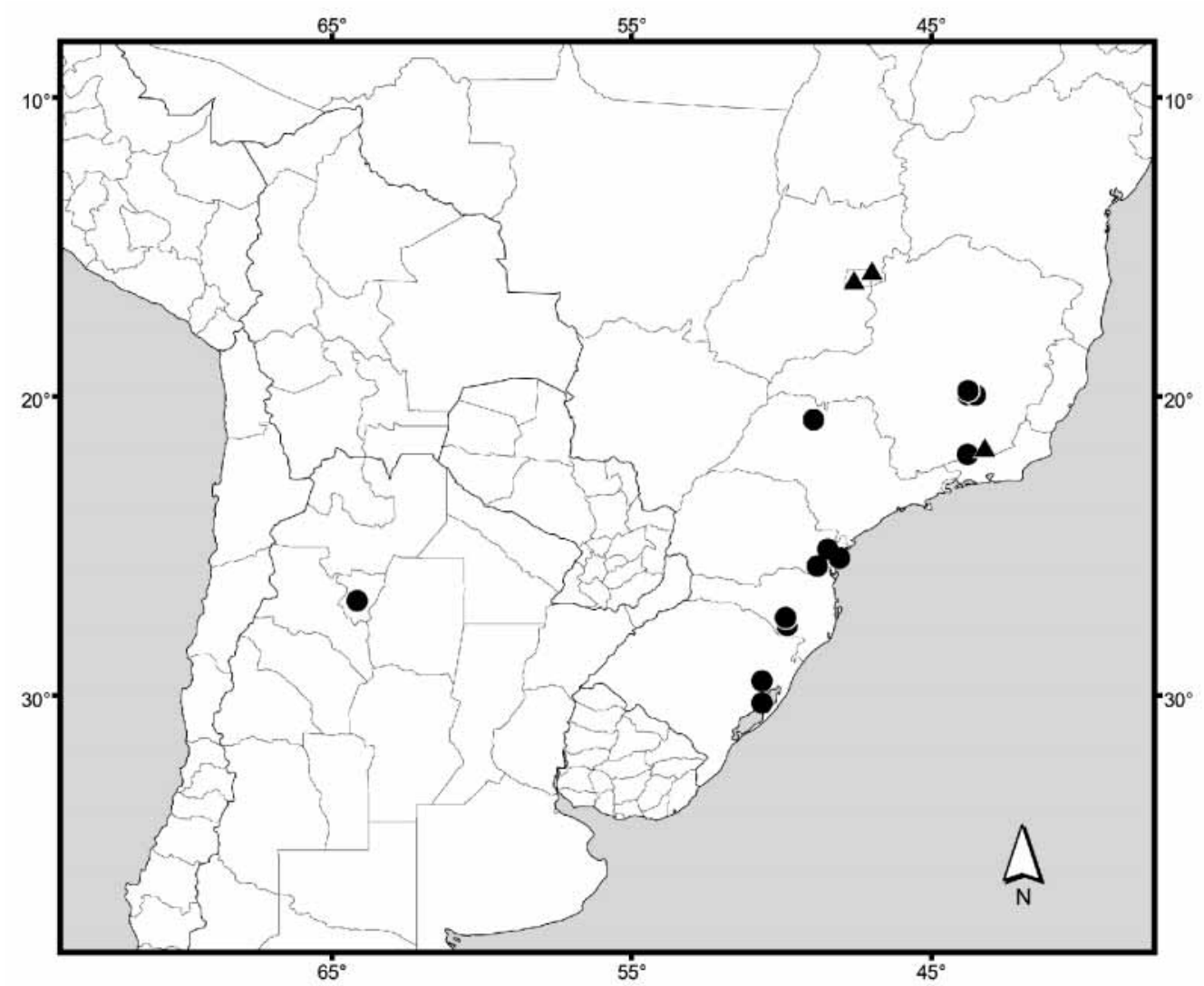

FIGURE 41. Distribution map of Sepedonea giovana sp. n. (triangles indicate sites in the literature for which we did not examine specimens).

The next monophyletic group after $S$. lindneri is characterized by (18) the shape of posterior surstylus (Fig. 20) and a character reversion, (24) distiphallus without a ventrally directed process. Sepedonea isthmi is the species that diverged after S. lindneri. This species has a widespread distribution: from Panama, Trinidad, Venezuela, and Colombia to Brazil (Amazonas, Goiás, São Paulo). This is the only species that has a well-developed anterior surstylus (19).

The next species on the cladogram, S. lagoa, is easily recognized and is characterized by the greatest number of autapomorphies: (20) posterior plates of the male $5^{\text {th }}$ sternites reduced; (25) distiphallus short and straight; and (18) posterior surstylus completely fused forming an elongate rod. There is also a homoplasious character (22) that characterizes 
this lineage, i.e., the epiphallus is not evident. Sepedonea lagoa is the most widespread species in the genus, ranging from Costa Rica to southern Brazil.

The next monophyletic group on the cladogram comprises eight species: ( $(S$. barbosai+ S. canabravana) ((S. neffi (S. giovana+S. guianica)) (S. telson (S. incipiens+S. trichotypa))). The group is defined by the following homoplasious characters: (15) the posterior margin of the male 4th sternite has a simple, medial process and (23) the epandrium bears a small prong. Except for $S$. guianica, which has a distribution in northwestern Brazil, all others occur in south, central and northeastern Brazil.

Freidberg et al. (1991) had previously suggested a close relationship between S. barbosai and S. canabravana and our analysis confirms their suggestion. On the cladogram these two species are sister groups. Both species have nearly sympatric distributions in central Brazil (Minas Gerais) and they share the characters: (27) the spermathecal duct at the junction with the spermatheca is divided into two portions, the portion closest to the spermatheca is narrow and (18) the shape of posterior surstylus similar (Figs. 12, 13).

The group of ( $S$. neffi (S. giovana + S. guianica) is defined by a homoplasious character (27): the spermathecal duct is divided into two portions, the portion closest to the spermatheca is narrow. Moreover, the distribution of $S$. neffi is conspicuously disjunct, with a gap of $4000 \mathrm{~km}$ between the only two sites where this species has been collected. It was recorded from Venezuela and Brazil (Espirito Santo) and is represented by very few specimens. Being supported by a single homoplasious character, the position of $S$. neffi on the cladogram is weakly established. With additional specimens and their dissection and study, the position and status of this species may change.

Sepedonea giovana and $S$. guianica are sister groups and are very similar morphologically. These two species differ morphologically in structures of the male genitalia, especially the surstylus. There are two homoplasious characters that also define their close relationship: (8) the male hindcoxal strap only bears setulae medially; and (15) the posterior margin of the male 4th sternite has two lateral processes.

The group of (S. telson (S. incipiens + S. trichotypa)) is based on: (15) the presence of a bilobed, medial process at the posterior margin of the male 4th sternite. Sepedonea telson occurs from central Brazil (Minas Gerais, Goiás) to southeastern and southern Brazil (São Paulo, Paraná, Santa Catarina and Rio Grande do Sul). Sepedonea incipiens and S. trichothypa are sister groups that share the following characters: (12) the presence of strong setulae near the posterior spiracle; and (18) the shape of the posterior margin of the posterior surstylus.

Our analysis confirms the monophyly of Sepedonea and that this genus is the sister group of Sepedomerus. The analysis, which was based on 27 morphological characters, resulted in a single cladogram, indicating that the phylogenetic relationships are relatively stable. Given the disjunct distribution of $S$. neffi and the paucity of specimens, the cladistic position of that species may change. We suggest that a study of the biogeography of these species may further clarify and corroborate the relationships within the genus. 
We thank Hollis B. Williams who provided technical support and produced the distribution map. We also thank Jay Abercrombie, Amnon Freidberg, L. Knutson and Masahiro Sueyoshi for reviewing a draft of this paper.

\section{References}

Barker, G.M., Knutson, L., Vala, J.-C., Coupland, J.B., \& Barnes, J.K. (2004) Overview of the biology of marsh flies (Diptera: Sciomyzidae), with special reference to predators and parasitoids of terrestrial gastropods. In: Barker, G. M. (ed.), Natural enemies of terrestrial molluscs. Wallingford, CAB International. Pp. 159-225.

Berg, C.O. (1973) Biological control of snail-borne diseases: A review. Experimental Parasitology, 33, 318330.

Berg, C.O. \& Knutson, L.V. (1978) Biology and systematics of the Sciomyzidae. Annual Review of Entomology, 23, 239-258.

Chock, Q.D., Davis, C.J. \& Chong, M. (1961) Sepedon macropus (Diptera: Sciomyzidae) introduced into Hawaii as a control for the liver fluke snail, Lymnaea ollula. Journal of Economic Entomology, 54, 1-4.

Cumming, J.M., Sinclair, B.J. \& Wood, D.M. (1995) Homology and phylogenetic implications of male genitalia in Diptera - Eremoneura. Entomologica Scandinavica, 26, 121-152.

Freidberg, A., Knutson, L. \& Abercrombie, J. (1991) A revision of Sepedonea, a Neotropical genus of snailkilling flies (Diptera: Sciomyzidae). Smithsonian Contributions to Zoology, 506, 1-48.

Gormally, M.J. (1988) Studies on the oviposition and longevity of Llione albiseta (Dipt.: Sciomyzidae)potential biological control agent of liver fluke. Entomophaga, 33, 387-395.

Knutson, L.V. (1987) Sciomyzidae. In: McAlpine J.F., et al. (coordinators), Manual of Neartic Diptera, Vol. 2. Agriculture Canada, Research Branch, Monograph, 28, 927-940. Otawa.

Knutson, L. \& Valley, K. (1978) Biology of a Neotropical snail-killing fly, Sepedonea isthmi (Diptera: Sciomyzidae). Proceeding of the Entomological Society of Washington, 80, 197-209.

Knutson, L. \& Vala, J.C. (2002) An evolutionary scenario of Sciomyzidae and Phaeomyiidae (Diptera). Annales de la Société Entomologique de France (n. s.), 38, 145-162.

Knutson, L.V., Steyskal, G.C., Zuska, J. \& Abercrombie, J. (1976) 64. Family Sciomyzidae. In: Papavero, N. (ed.), A catalogue of the Diptera of the Americas south of the United States. Museu de Zoologia da Universidade de São Paulo. 24 pp.

Maharaj, R., Appleton, C.C., \& Miller R.M. (1992) Snail predation by larvae of Sepedon scapularis Adams (Diptera: Sciomyzidae), a potential biocontrol agent of snail intermediate hosts of schistosomiasis in South Africa. Medical and Veterinary Entomology, 6, 183-187.

Marinoni, L. \& Carvalho, C.J.B. de. (1993) Cladistic analysis of Protodictya (Diptera, Sciomyzidae). Proceedings of the Entomological Society of Washington, 95, 412-417.

Marinoni, L. \& Knutson, L. (1992) Revisão do gênero neotropical Protodictya Malloch, 1933 (Diptera, Sciomyzidae). Revista Brasileira de Entomologia, 36, 25-45

Marinoni, L. \& Mathis, W.N. (2000) A cladistic analysis of Sciomyzidae Fallén (Diptera). Proceedings of the Biological Society of Washington, 113, 162-209.

Marinoni, L., Steyskal, G.C. \& Knutson, L. (2003) Revision and cladistic analysis of the Neotropical genus Thecomyia Perty (Diptera: Sciomyzidae). Zootaxa, 191, 1-36.

Mello, D.A. \& Bredt, A. (1978) Estudos populacionais de cinco espécies de Sciomyzidae (Diptera - Insecta) no norte de Formosa, Goiás. Ciência e Cultura, 30, 1459-1464.

McAlpine, J.F. (1981) Morphology and Terminology - Adults. In: McAlpine, J. F., et al., (coordinators), Manual of Nearctic Diptera, Vol. 1. Agriculture Canada, Research Branch, Monograph 27, 9-63.

Neff, S.E. \& Berg, C.O. (1966) Biology and immature stages of malacophagous Diptera of the genus Sepedon (Sciomyzidae). Bulletin of the Agriculture Experiment Station, Virginia Polytechnic Institute, 566, 1-113.

Rivosecchi, 1. (1992) Diptera Sciomyzidae. In Fauna d'Italia, 30: 270 pp., Bologna, Edit. Calderini.

Steyskal, G.C. (1973) A new classification of the Sepedon group of the family Sciomyzidae (Diptera) with two new genera. Entomological News, 84, 143-146. 